\title{
«Индустрия 4.0" и современный сервис: особенности и тенденции
}

А. Соломатин ${ }^{1}$

УДК 658.5 | ВАК 05.27 .06

\begin{abstract}
В условиях четвертой промышленной революции, широко известной также под названием "Индустрия 4.0", владельцы современного промышленного оборудования, разрабатываемого с применением наукоемких технологий, сталкиваются с прогрессирующими трудностями в части его эффективного использования, а зачастую и просто поддержания в исправном, работоспособном состоянии. Широкое распространение на производствах информационных технологий, внедрение в состав отдельных установок, сборочных линий и предприятий в целом киберфизических систем делают задачу грамотной эксплуатации производственных мощностей собственными силами всё более трудноразрешимой. Особенно это справедливо для предприятий, работающих в области производства электронных изделий, компонентов, сборки печатных плат и узлов. В статье рассматриваются современные подходы к обеспечению сервисного обслуживания промышленного оборудования.
\end{abstract}

\section{КОНЦЕПЦИИ СЕРВИСА:}

\section{ТРАДИЦИОННЫЙ ПОДХОД}

Традиционно для обслуживания оборудования промышленность прибегает кпомощи различных сервисных организаций. В настоящее время существует целый ряд концепций обеспечения технического сервиса и поддержки. Не вдаваясь в теорию, можно условно разделить их на три направления:

1. Сервис, обеспечиваемый соответствующими структурными подразделениями организацииэксплуатанта.

2. Сервис, предоставляемый сторонней специализированной фирмой.

3. Сервис силами организации-поставщика (или производителя) оборудования.

Первый вариант, безусловно, весьма затратен для собственника производства, поскольку подразумевает необходимость содержать собственную сервисную службу (порой весьма многочисленную) и самостоятельно нести расходы, связанные с поддержанием и повышением квалификации обслуживающего персонала. Выигрыш в оперативности и сокращении времени простоев оборудования вследствие выполнения планового обслуживания или ремонтных работ, который, теоретически, должен достигаться за счет использования собственных ресурсов организации, зачастую не реализуется на практике Причиной тому уже упомянутая постоянно возрастающая сложность оборудования и связанных с его эксплуатацией

ООО «Остек-СМТ», руководитель службы сервиса. технических и технологических операций, относящихся как каппаратной, так и программной составляющим. Как правило, силами собственного сервисного подразделения удается быстро разрешить лишь наиболее простые, типовые вопросы и проблемы. В остальных случаях неизбежно обращение за консультациями и технической поддержкой к организациям-поставщикам, с привлечением их инженерно-технического персонала, владеющего необходимыми знаниями и навыками, а также специфическим инструментарием.

Второй вариант, а именно услуги специализированных сервисных подрядчиков, может обеспечивать весьма высокое качество, но при этом быть весьма дорогостоящим, поскольку сервис является основным источником прибыли подобных организаций. Позволить же себе содержать широкую сеть подразделений (специалистов) в регионах могут далеко не все, что сказывается на скорости реакции на обращения заказчиков. Ктому же, будучи организациями, не связанными с поставщиками оборудования непосредственно, такие фирмы часто вынуждены прибегать к консультациям и запрашивать поддержку поставщиков, что, опять-таки, отрицательно сказывается на оперативности.

Третий вариант реализуется двояко. Если компанияпоставщик развивает собственное сервисное подразделение как центр генерирования прибыли, то есть как отдельный специализированный бизнес, то, как правило, услуги такого подразделения - лучшее, что может получить заказчик с точки зрения качества, наполнения и оперативности приобретаемыхуслуг. В то же время это просто 
качественный технический сервис, которым в наше время сложно кого-либо удивить, равно как и просто качественным, технически «продвинутым» продуктом (это утверждение справедливо практически для любой отрасли и сферы деятельности).

\section{КОНЦЕПЦИИ СЕРВИСА: ПЕРСПЕКТИВНЫЙ ПОДХОД}

Более эффективной и перспективной можно считать продуктово-сервисную систему (ПСС), когда компанияпоставщик стремится обеспечить заказчика не просто отвечающим его запросам решением или продуктом и далее качественным техническим сервисом как таковым, но когда сервис сам по себе не является "товаром" и реализуется как часть комплексного решения, призванного не только снабдить заказчика необходимыми ему средствами достижения своих целей, но и обеспечить достижение целей как таковых. Иными словами, правильно разработанная ПСС приносит заказчику не набор требуемого оборудования и услуг (пусть и весьма совершенных), а достижение желаемого результата - например, производство определенного вида изделий с гарантированным качеством, производительностью, по требуемой технологии и с четко прогнозируемым временем простоя.

Практика создания ПСС, наработанная в компании "Остек-СМт» (рис. 1), показывает, что именно данный подход оказывается наиболее эффективным как для потребителя, так и для поставщика, обеспечивая последнему преимущество в конкурентной борьбе за реализацию проекта.

Однако, следует учесть, что ПСС является полноценной и конкурентоспособной только в том случае, когда она наполнена современными и перспективными решениями из области технического и так называемого клиентского сервиса. Немаловажную роль играют и технологии общения с заказчиком. Реализация пСС требует от поставщика отказа от традиционных взглядов на самоценность продукта и / или услуг. Сервисное подразделение организации, предлагающей своим заказчикам решения в рамках ПСС, не обязательно должно быть прибыльным или даже самоокупаемым. Общий эффект данной модели достигается в большей мере за счет реализации потенциала сервиса как части комплексного проекта по оснащению или модернизации производства.

Основными составляющими ПСС для большинства отраслей промышленности, включая сферу поверхностного монтажа электронных компонентов, являются:

- сам продукт (станки, машины, механизмы);

- пакет традиционных услуг технического сервиса, включающий плановое техническое обслуживание, диагностику и ремонт оборудования;

- система технической поддержки, ориентированная на удаленное решение вопросов заказчика;

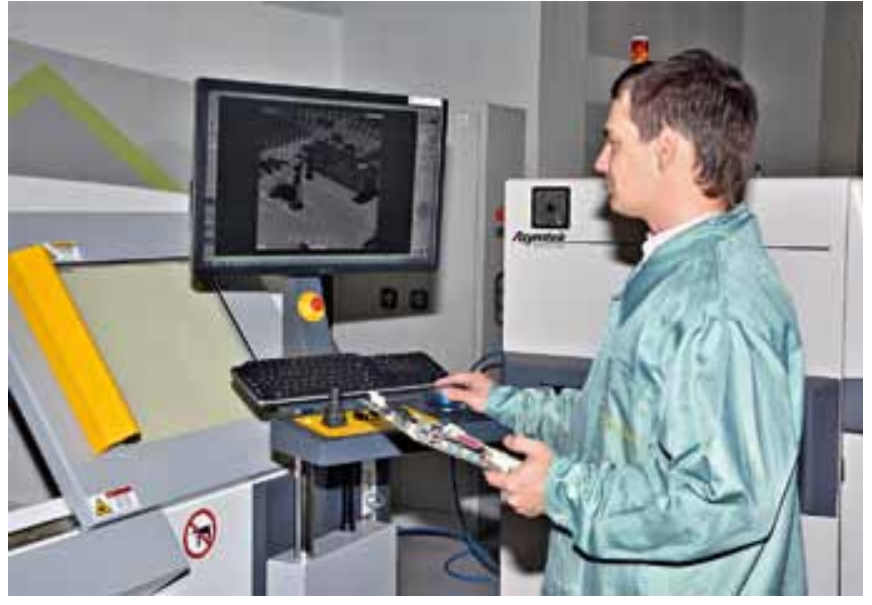

Рис. 1. Сервис-инженер Остек-СМТ за работой

- услуги по консультированию заказчика в технологических вопросах (и собственно разработка и внедрение необходимых для заказчика технологий);

- программы тренингов разного уровня, ориентированные на всестороннюю подготовку операторов, технологов и других занятых на производстве сотрудников заказчика;

- всевозможные аспекты клиентского сервиса

Последнее понятие не имеет формального и однозначного определения. По сути, под ним понимается культура взаимодействия с заказчиком и способность удовлетворить все его запросы наиболее комфортным, оперативным и предпочтительным для самого заказчика образом.

Из перечисленного на российском рынке традиционно недооцениваемой поставщиками составляющей является техническая поддержка. Если, к примеру, в сфере IT-технологий, в силу специфики отрасли, данная услуга хорошо развита, то применительно к промышленному оборудованию она часто оказывается по остаточному принципу. Вероятно, связано это с неполным пониманием поставщиками того, как можно эффективно монетизировать техническую поддержку (а такое желание неизбежно возникает, поскольку техподдержка потребляет ресурсы компании), а также того, какие потенциальные выгоды для репутации компании сулит способность всесторонне консультировать заказчика, решая большую часть вопросов удаленно. На рынке, в свою очередь, пока не развит серьезный спрос на подобную услугу, поскольку она просто незнакома большинству потребителей: заказчики готовы оплачивать конкретные операции вроде технического обслуживания, тогда как техническая поддержка является для многих абстракцией. Секрет успешного подхода здесь кроется в том, чтобы предлагать техническую поддержку не как самостоятельную услугу, а как естественную составляющую комплексного решения - продуктово-сервисной системы. 


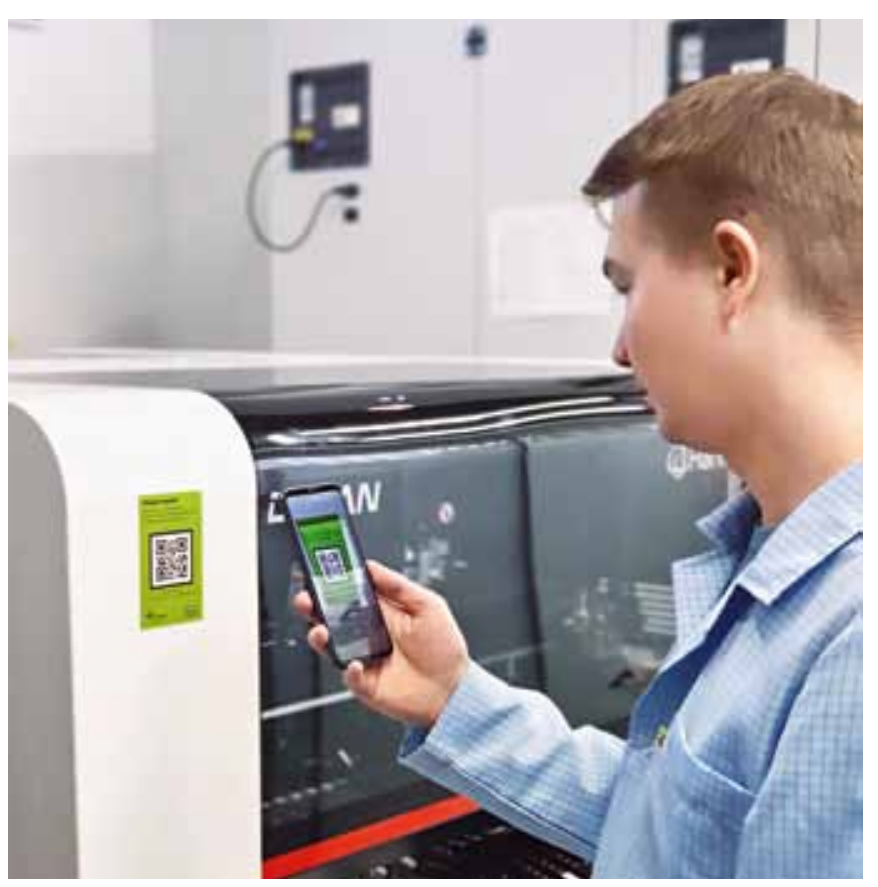

Рис. 2. Отправка обращения в приложении Ostec Service

Не менее традиционной проблемой российского рынка является клиентский сервис. Ключевую роль в предоставлении качественного клиентского сервиса играют отнюдь не пресловутая клиентоориентированность и даже не оптимальным образом выстроенные бизнес-процессы организации-поставщика: они являются всего лишь следствием корпоративной культуры, системы ценностей и взаимоотношений внутри компании. Не менее важно умение находить здравый баланс между такими неизбежными в работе сервисных подразделений вещами, как стандартизация, высокая трудовая дисциплина, глубокая автоматизация бизнес-процессов, с одной стороны, и поощрение свободного мышления сотрудников и творческого подхода к работе с клиентами - с другой.

Следует особо выделить важность технического аспекта организации связи между заказчиком и поставщиком сервисных услуг. Даже при существующем изобилии каналов коммуникации наблюдается постоянное развитие в этой сфере, появляются новые технические решения. Задача поставщика сводится к тому, чтобы предоставить заказчику максимум свободы в выборе средств передачи информации: заявки и запросы могут поступать по телефону, электронной почте, через веб-сайты и мессенджеры. В то же время во избежание хаоса при обработке входящей информации и дальнейшей коммуникации с заказчиком поставщик обязан использовать соответствующие средства автоматизации бизнес-процессов и CRM-системы, способные свести поток входящих данных в "одно окно", а затем правильным образом распределить их внутри организации.
В качестве примера успешной реализации концепции сервиса как части продуктово-сервисной системы на рынке оборудования для производства радиоэлектронной аппаратуры можно привести опыт компании "Остек-СМТ", предоставляющей своим заказчикам весь комплекс услуг, технических и организационных решений, включая программные продукты собственной разработки. Надо отметить, что в компании ведется непрерывная работа над всеми составляющими ПСС. Особое внимание уделяется вопросам обучения персонала заказчиков с использованием современных информационных технологий, организации эффективной технической поддержки с минимальным временем реакции на заявки клиентов и внедрению на предприятиях целого ряда программных решений с целью обеспечения эффективности более («Умная линия») и менее ("Умное рабочее место») автоматизированных производств.

Также в 2020 году компания "Остек-СМТ» предложила своим заказчикам мобильное сервисное приложение Ostec Service (рис. 2), позволяющее сделать процесс подачи заявки или обращения по оборудованию максимально быстрым и удобным. В то же время приложение обеспечивает абсолютную прозрачность рабочего процесса (заказчик может непосредственно наблюдать всю историю по обработке своей заявки или заявки, отправленной его подчиненными, в сервисную службу "Остек(МТ»), а также высокий уровень защищенности информации, передаваемой через приложение. Приложение может работать на смартфонах с любыми операционными системами, прошло пилотное тестирование и завоевывает популярность у пользователей.

Суммируя сказанное, необходимо отметить, что спрос и запросы на сервисные услуги технически сложного оборудования диктуются направлением научно-технического прогресса в каждой определенной отрасли промышленности. Однако, есть общая тенденция, прослеживаемая во всех секторах экономики большинства развитых и развивающихся стран мира - это неизбежное влияние четвертой промышленной революции, повсеместное внедрение на производствах аналога уже известного многим обывателям Интернета вещей (IоT) и связанного с ним всеобъемлющего проникновения информационных технологий на уровне самого производства. Отдельные единицы оборудования, персонал, производство, контрагенты, обслуживающие организации и средства коммуникации между ними превращаются в единый комплекс. Поэтому победа в соревновании на рынке сервисных услуг достанется предприятиям, способным органично работать в рамках данного единого комплекса, которые не просто удовлетворяют все насущные и перспективные потребности клиента, но и непрестанно предлагают перспективные решения по совершенствованию и развитию производств. 


\section{Что скрывается за передовым производством?}

\section{Живой процесс}

